\title{
Rebuilding School Culture and Promoting Teachers' Professional Development
}

\author{
Cunrong Wang* \\ School of Mathematics and Statistics, Qilu University of Technology (Shandong Academy of Sciences), Jinan 250353, China \\ *Corresponding author: Cunrong Wang, 1191984686@qq.com

\begin{abstract}
School culture is an important carrier for teachers' professional development. It is also a double-edged sword that can either promote or hinder the professional development of teachers. The improvement of teachers' professional development fundamentally lies in the reconstruction of school culture. School culture is derived from the school system because the system creates the environment that determines professional development. The improvement of school culture is achieved through learning because learning can create a solid platform for teachers' professional development. Principals should rebuild their relationships with their schools and teachers, while teachers should rebuild their relationships with other teachers and their students as well as between their own practices and educational theories.
\end{abstract}

Keywords: School culture; School culture construction; Teacher professional development

Publication date: October 2021; Online publication: October 29, 2021

\section{Introduction}

Majority of people believe that the professional development of teachers depends on professional knowledge, teaching skills, and the awareness of professional development. In addition to that, there are many others that hold on to the belief that school culture has insignificant influence on teachers' professional development and that principals and teachers have built various relationships under the guidance of experience.

School culture is an important carrier for teachers' professional development. It is a double-edged sword that can either promote or hinder the professional development of teachers. The fundamental basis of teachers' professional development lies in the reconstruction of school culture; thus, it can even be regarded as an important guarantee of teachers' professional development.

\section{Ways to rebuild school culture}

School culture is derived from the school system because it is the system that creates the environment for teachers' professional development. The improvement of school culture is accomplished through learning. This is because learning, by teachers and administrators alike, can create a solid platform for teachers' professional development.

\subsection{Derivation of school culture from the school system: creating a harmonious environment for teachers' professional development}

A school's culture centers on its common values, value judgments, and value orientation. Many teachers have or know advanced educational concepts but some of their behaviors are contrary to their espoused conceptual understanding. For example, most teachers already know that students should be the ones 
responsible for their own learning, but they do not provide adequate time and space for students to exercise their own thought process. There are also cases where teachers use vulgar language and behave inelegantly although they know the principle of being a good exemplar. Moreover, most teachers already have a firm understanding of their duty to teach and educate, but they are arrogant in the teaching process. Each teacher has his or her own concept system; therefore, the differences between the systems translate into various behavioral modes and teaching styles. Incorporating external value systems into their concept systems should be the priority in reconstructing the school culture, albeit its difficulty. It has been habitual in terms of the approach values of "liking the old and hating the new"; as John Dewey had mentioned, "Every person insists on holding on to what the old ideas have even when he is forced to give up the logical basis of the old ideas."

Most schools provide institutional support for rebuilding internal culture. The system is an important guarantee for schools to carry out all their work as well as regulating and incentivizing teachers' professional development. Nothing can be accomplished without following the norms and standards but when there are too many rules, the benefits of individual differences are lost. Lawrence Stenhouse, a British curriculum theorist, believes that the mission of education is to give people more freedom and creative power ${ }^{[1]}$. Under a surfeit of regulations, especially unreasonable ones, teachers' freedom and creativity are restricted, thus restraining their professional development. A social order that is fashioned on the principle of rationality does not necessarily promote freedom; in fact, they are often used for tyranny and power to deny individuals the opportunity for rational thought and the capacity to act as free men ${ }^{[2]}$. Indeed, some schools have forged the "Procrustean bed" in their education system, where teachers' individual distinctions - both good and bad - have been sculpted to fit the pre-existing parameters.

Teaching reflection is an effective method for professional development. Some schools have institutionalized teaching reflection and confined it into a task-oriented project ${ }^{[3]}$. As exemplified by a school, the regulations required teachers with more than five years of teaching experience to write three reflective diaries every week, each of at least 500 words; even for teachers with less than five years of experience, they are not exempted from the mandate, where they have to reflect after each class, writing at least 300 words with their lesson notes. At the end of each week, the leader of the teaching and research group would collect these reflections and submit them to the Teaching Guidance Office for inspection and record. Initially, teachers were able to hand in their teaching reflections in a timely manner, but the situation soon changed; teachers began to complain that the reflection process is taking too much time and energy. In turn, this initiative that aimed to promote the teachers' professional development became stranded due to the lack of appreciation of its value among teachers.

As school culture is derived from the school system, it may be beneficial to avoid rigid systems that suppress, restrict, and hinder the professional development of teachers in order to build a school culture that guides, encourages, and promotes teachers' professional development. For example, there is a school that has established a system of appointing head teachers as counselors as the highest level of professional recognition ${ }^{[4]}$. The issue that has been raised concerns the kind of head teachers that can become counselors. Only when the final decision on all the activities of a class is returned from the teacher to the students, then the head teacher can be appointed as a counselor.

The "instructor" mechanism has become a catalyst for a new type of teaching relationship in schools, accelerating the understanding of healthy teacher-student relationships. The student-centered concept has become the starting point and foothold of every teacher's thought process and work. This is the most important cultural cornerstone in schools. Giving another example, the same school has established a system where teachers would participate in the decision-making process of the school. Teachers are given the opportunity to participate in both short-term policy making and long-term decision-making that would affect the school planning and teachers' long-term development. Involving teachers in the school 
management and governance has become the cornerstone of a harmonious and democratic cultural environment throughout the whole institution.

\subsection{Improving school culture through learning: building a solid platform for teachers' professional development}

Learning here does not mean the imparted one-way knowledge from training or listening to reports, neither does it involve merely reading or studying. The concern of learning here is the cognitive and cultural practice of constructing the meaning of the objective world, the social and political practice of constructing interpersonal relationships, as well as the ethical and existential practice of self-cultivation ${ }^{[5]}$. This kind of learning considers communication and dialogue as its main process and the building of rational relationships between learners and the objective world as well as with other people as its main purport. Building rational relationships are integral in constructing the school culture. Schools are social systems. Schools should be learning communities in a modern, learning-oriented society. School leaders and teachers need to be learners.

\subsubsection{Principals rebuilding relationships with schools and teachers through learning}

Principals need to realize that they are not only the administrators of their schools, but also the builders and disseminators of school culture. It is the responsibility of principals to pave the goals, contents, and path for the development of the school culture, and they have an obligation to create a suitable environment for the reconstruction of school culture. Principals need to realize that schools are not only for cultivating students, but also for the development of the teachers. Teachers are not only there to address students' problems nor confined to explore teaching and learning theories or practices, but they are also decision makers of the school. In addition to providing a suitable environment for teachers to carry out teaching practices and research, schools should involve teachers in their decision-making. It has been widely recognized that action research for teachers is an important strategy for their professional development. In fact, their participation in decision-making for the school is also important for their own professional development. Many schools have carried out the practice and research of school-based curriculum in the new round of curriculum reform. If teachers are given the opportunity to actively participate in their schools' curriculum construction process, they would be able to make fuller use of the resources, look for opportunities, and improve their own skills in curricular decision-making, thus promoting the improvement of their professional quality.

However, school organization and management tend to look highly upon the hierarchical perspective of Max Weber under the guidance of modern management theory. Teachers are at the bottom of the bureaucratic management system, and their actions are controlled by administrative personnel, including the principal, dean, teaching affairs office, and supervision office. Teachers are subjected to lesson planning inspection systems, homework arrangements, correction regulations, attendance systems, and all kinds of unified examination ranking evaluation constraints. Teachers who work under such management for a long time tend to lose their individuality and subjectivity, thus having no part in the schools' decision-making process. How then to untie the constraints that these teachers experience? How to cultivate teachers' personalities? How to stimulate teachers' subjective consciousness and decision-making consciousness? How to improve the role of teachers and their decision-making skills? These are all urgent problems that principals need to solve through learning.

\subsubsection{Relationships that teachers need to rebuild in their learning}

Teachers need to rebuild the relationship between educational practice and educational theories. There is 
an unreasonable expectation among teachers whereby they assume that educational and teaching theories can solve all the problems encountered in educational and teaching practices.

However, in reality, many of the issues that teachers encounter in their teaching practices are neither straightforward nor simple enough to be able to clearly judge right from wrong alike mathematical problems or self-solving problems with only one solution. There are endless solutions to a problem, but a good solution would prepare for the advent of a bigger problem arising from that one issue ${ }^{[6]}$. This determines the complexity and challenge in education and teaching practices. It is impossible for teachers to meet the ideals of educational theories because educational practices are more complex than the generalizations and abstractions that educational theories admit. However, if the expectations of educational theories are overly suppressed, teachers may begin to dismiss educational theories as useless and even omit the value that educational theories offer as the foundation of teachers' professional development. Without the support of educational theories, professional development can neither go far nor high. In view of all these, educational theories should be neither be deified, nor taken for granted.

Teachers should not expect to see an immediate effect after learning certain teaching theories. Instead, teachers should take time to reflect on their own educational practices in order to revise and perfect their educational practices from the perspective of the educational theories that they have learned. Only in this way can teachers improve the integration of educational theories into their educational practices.

Second, teachers need to rebuild their relationship with other teachers. The rebuilding of these relationships requires the rebuilding of teacher culture. Teacher culture is an important part of the school culture, and it is closely related to teachers' professional development. In an in-depth analysis on teacher culture by Hargreaves, a Canadian scholar, there are four cultures that are commonly seen among teachers: individualism, factionalism, artificial cooperation, and natural cooperation ${ }^{[7]}$.

In the current era of advocating cooperative culture, the society often only perceives the negative side of the individualistic culture and factionalist culture. For example, individualistic culture tends to hinder knowledge sharing and conversion, thus leading to closed mental models, whereas factionalism tends to create tension and indifference among teachers while hindering their sense of responsibility for external innovation. However, people have failed to see their benefits. From a different perspective, individualistic culture does not only protect teachers' individual personalities and professional development characteristics, but also their subjectivity as well as professional autonomy. Factionalist culture based on grade division does not only facilitate horizontal curriculum integration within the same grade, but also improve teachers' skills in teaching within each group to a certain extent. In fact, individualistic culture and factionalist culture should be appreciated in a dialectical manner while avoiding their shortcomings in reality and making good use of their strengths.

In view of teachers' professional development, it has become a consensus that the natural cooperation culture is the most ideal culture that teachers should aim for. However, natural cooperation cannot not be formed easily or quickly; it is inherently long and difficult to form such a culture. Natural cooperation can be developed and perfected only by absorbing the essence of individualism and factionalism while discarding their negative qualities.

Third, teachers need to rebuild the relationship with their students. In traditional teaching, a teacher's authority is reflected in three ways: students must learn what has been taught by the teacher, meet the requirements that have been set by the teacher, and obey the instructions given by the teacher ${ }^{[8]}$. The authority held by teachers limits students' thinking space, hinders the growth of students' creativity, and loses many resources that would benefit in promoting teachers' professional development.

The goal of students' healthy growth along with teachers' professional development calls for a new teacher-student relationship, which is centered on equal dialogue. The classroom is the main place to establish this, and dialogic teaching is an important way to realize equal dialogue. In dialogic teaching, 
teachers are the promoters and cooperators of students' learning. Teachers should insist on the understanding, tolerance, equality, and intersubjectivity of dialogues, as well as to eliminate their own authority. In the dialogic classroom, the use of language is not merely to question or answer, but rather to express one's own views and opinions. Its purpose is not to prove a point or eliminate differences, but to explore new knowledge by listening to different views as well as to build a culture of mutual pride and respect for the different ideas proposed by the teachers and other students.

The new teacher-student relationship, which dispels the authority of teachers and places all voices on an equal footing, does not dismiss the important role of teachers in students' learning. Several scholars ${ }^{\text {[9] }}$ have given teachers a new title in dialogue teaching: "interactional otherness." Teachers' life experiences, social experiences, knowledge level, skills, and accomplishments determine their "otherness." Teachers are thus interlocutors of "otherness" in the classroom learning community. Their heterogeneous "otherness" enables them to promote the development of students' introspective and critical thinking. Having a certain conceptual distance between students and teachers would provide adequate space for students to actively develop their own creativity and grow into independent learners.

\section{Conclusion}

School culture is an important carrier for teachers' professional development. It is also a double-edged sword that can either promote or hinder the professional development of teachers. The improvement of teachers' professional development fundamentally lies in the reconstruction of school culture. School culture is derived from the school system because the system creates the environment that determines professional development. The improvement of school culture is to be achieved through learning because learning can create a solid platform for teachers' professional development. Principals should rebuild their relationships with their schools and teachers, while teachers should rebuild their relationships with other teachers and their students as well as between educational theories and their own practices.

\section{Funding}

This research was supported by the Qilu University of Technology (Shandong Academy of Sciences) Teaching Research Project (2020szzx23) and the Second Batch of New Engineering Research and Practice Specialty Reform Project (E-RCZN20201029).

\section{Disclosure statement}

The author declares that there is no conflict of interest.

\section{References}

[1] Shi L, 2005, Curriculum Theory - Fundamentals, Principles, and Problems of Curriculum, Education Science Press, Beijing, 172.

[2] Wright Mills C, 2005, Sociological Imagination [Chen Q, et al., Trans.], Life, Reading, New Knowledge Sanlian Bookstore, Beijing, 183.

[3] Zhou J, 2006, Reflection on "Fever" in Teaching, China Education News, (3).

[4] Li X, 2004, Creating School Culture. People's Education, (3-4): 10-11.

[5] Manabu S, 2005, The Joy of Learning - Towards Dialogue [Zhong Q, et al., Trans.], Education Science Press, Beijing, 38-42. 
[6] Manabu S, 2005, The Joy of Learning - Towards Dialogue [Zhong Q, et al., Trans.], Education Science Press, Beijing, 223.

[7] Hargreaves A, 1994, Changing Teachers, Changing Times: Teachers' Work and Culture in the Postmodern Age, Cassell, London, 166.

[8] Sun X, 2000, On the Relationship between Teachers and Students in Teaching. Educational Theory and Practice, (10): 12-15.

[9] Manabu S, 2005, The Joy of Learning - Towards Dialogue [Zhong Q, et al., Trans.], Education Science Press, Beijing, 48. 